\title{
Selexipag Therapy for Raynaud Phenomenon-induced Severe Digital Ischemia in Intravenous Epoprostenol Responders With Connective Tissue Disease
}

David Langleben (1D, MD, Center for Pulmonary Vascular Disease, Azrieli Heart Center, Division of Cardiology; Laeora Berkson, MD, Division of Rheumatology, Jewish General Hospital and McGill University; Sandra Chartrand, MD, Division of Rheumatology, Hôpital Maisonneuve-Rosemont and Université de Montreal, Montreal, Quebec, Canada. Dr. Langleben has served as a consultant and speaker for Janssen. Address correspondence to Dr. D. Langleben, Room E-206, Jewish General Hospital, 3755 Cote Ste Catherine, Montreal, QC H3T 1E2, Canada. Email: david.langleben@mcgill.ca. Selexipag is approved for the treatment of pulmonary arterial hypertension (PAH) in Canada. None of the agents already used clinically for Raynaud phenomenon (RP) and digital ischemia, including calcium blockers, phosphodiesterase-5 inhibitors, and others, are approved for RP. This was, therefore, compassionate use therapy. We did not require institutional review board approval to give the therapy. Both subjects agreed to receive selexipag, after an explanation of its actions and side effects profile, as we do routinely for patients with PAH, and with the understanding that it would be stopped if the subjects felt there was no benefit. Both subjects gave signed written consent to publish their photographs in an anonymous fashion.

Raynaud phenomenon (RP) in connective tissue disease (CTD) can be resistant to oral vasodilator therapy, resulting in uncontrollable digital ischemia. Intravenous (IV) prostanoids are often used, but the benefit can be transient and not all patients respond. Selexipag is an orally active selective IP-type prostanoid receptor agonist used in pulmonary arterial hypertension.

We describe 2 patients where selexipag significantly reduced digital ischemia after failure of other oral vasodilating agents. Subject 1 with undifferentiated CTD had impressive healing of her fingers (Figure 1) and subject 2 with systemic sclerosis (SSc) had a similar effect on her toes (Figure 2). Both patients had previously responded to intermittent IV epoprostenol infusions but had rebound ischemia between infusions. There was a gap of at least 2 weeks between the last epoprostenol infusion and the initiation of selexipag. In both cases, selexipag was initiated in December, and significant improvement was evident by the end of January, despite the frigid Montreal weather. Refractory RP is a significant source of morbidity and reduced quality of life in CTD patients ${ }^{1,2,3}$. A placebo-controlled study of selexipag's effects on RP in SSc was negative ${ }^{4,5}$, but patients were excluded if they received prostacyclin or its analogues in the prior 3 months, and there is no information on how many had received IV prostanoids or whether they responded to them.
Is it possible to identify a population that will respond to selexipag based on prior responsiveness to IV prostanoid infusions? Demonstration of success with selexipag in such a population would liberate them from the burden of infusions. The effects of selexipag deserve further investigation in enriched populations with digital ischemia that are responsive to IV prostanoids. A positive outcome would enhance personalized medicine for patients with CTD and RP.

\section{REFERENCES}

1. Wigley FM, Flavahan NA. Raynaud's phenomenon. N Engl J Med 2016;375:556-65.

2. Ratchford EV, Evans NS. Raynaud's phenomenon. Vasc Med 2015;20:269-71.

3. Herrick AL, Wigley FM. Raynaud's phenomenon. Best Pract Res Clin Rheumatol 2020;34:101474.

4. Denton CP, Hachulla E, Riemekasten G, Schwarting A, Frenoux JM, Frey A, et al; Raynaud Study Investigators. Efficacy and safety of selexipag in adults with Raynaud's phenomenon secondary to systemic sclerosis: a randomized, placebo-controlled, phase II study. Arthritis Rheumatol 2017;69:2370-9.

5. Seibold JR, Wigley FM. Editorial: clinical trials in Raynaud's phenomenon: A spoonful of sugar (pill) makes the medicine go down (in flames). Arthritis Rheumatol 2017;69:2256-8. 


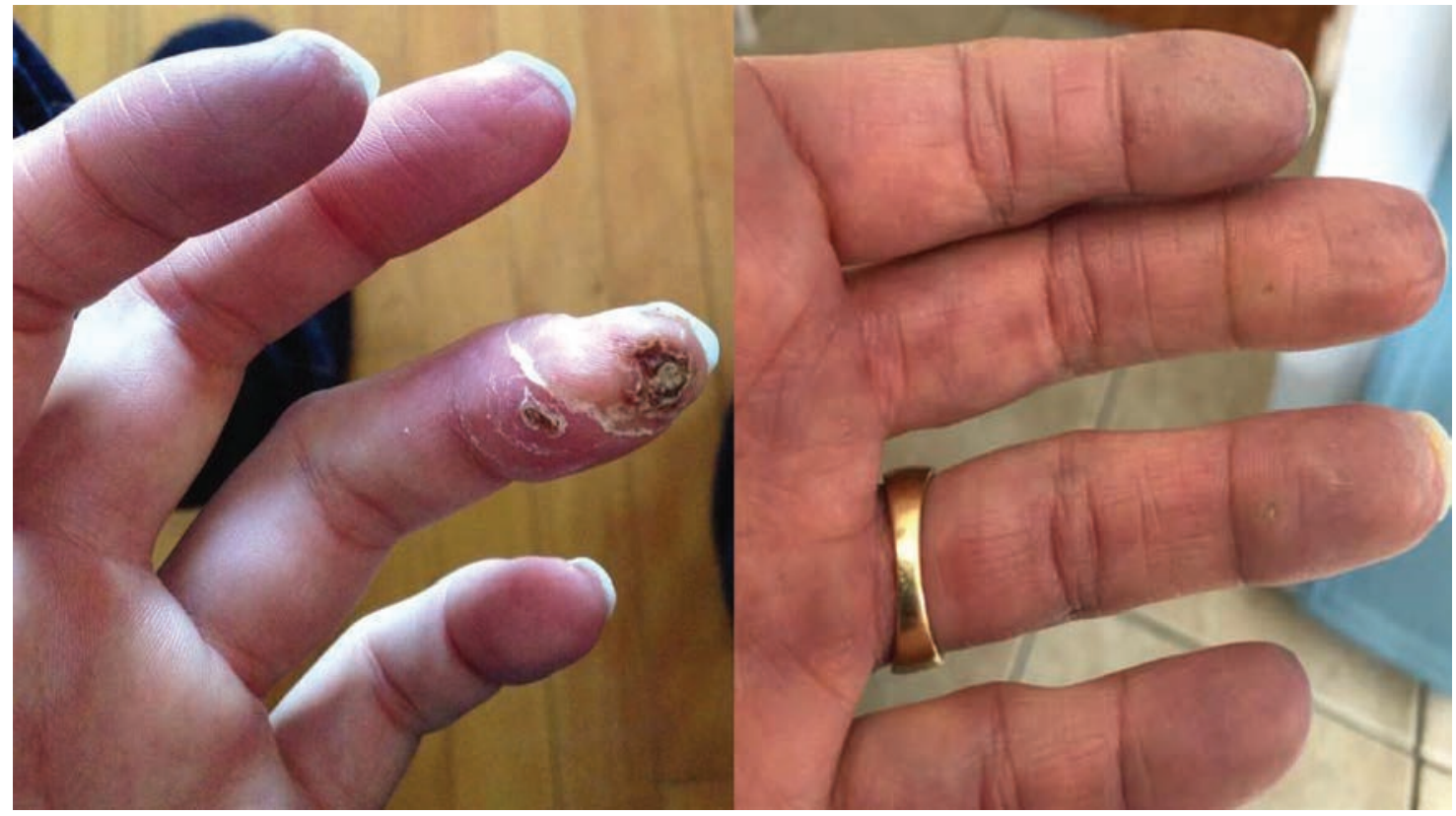

Figure 1. Hand and finger perfusion and skin lesions in subject 1, before (left) and after (right) selexipag therapy.

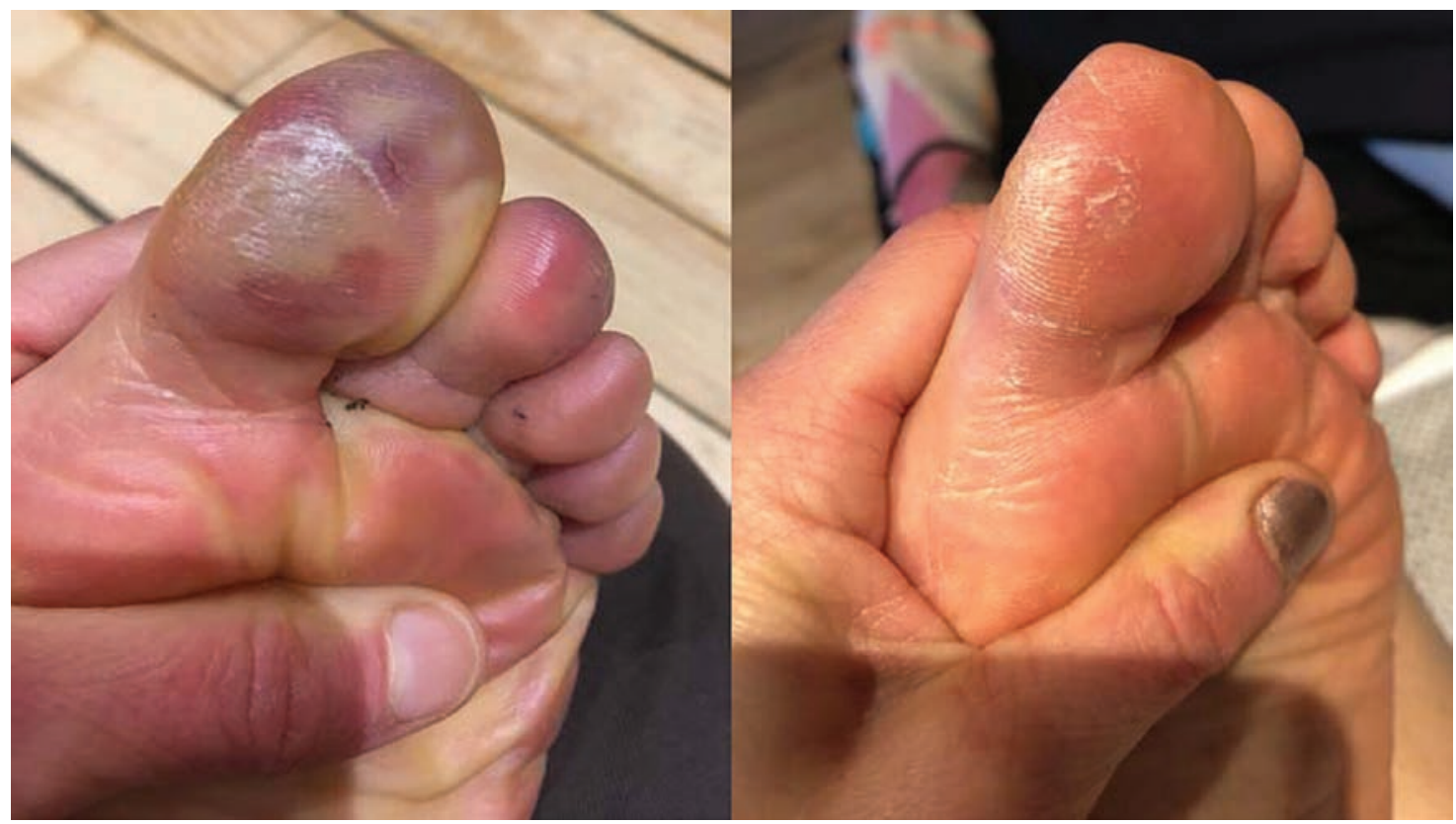

Figure 2. Foot and toe perfusion and skin lesions in subject 2, before (left) and after (right) selexipag therapy. 